Jansen, J., Weert, J.C.M. van, Wijngaards-de Meij, L., Dulmen, S. van, Heeren, T.J., Bensing, J.M. The role of companions in aiding older cancer patients to recall medical information.

\begin{tabular}{|l|l|}
\hline $\begin{array}{l}\text { Postprint } \\
\text { Version }\end{array}$ & 1.0 \\
\hline $\begin{array}{l}\text { Journal website } \\
\text { Pubmed link }\end{array}$ & $\underline{\text { http://dx.doi.org/10.1002/pon.1537 }}$ \\
\hline DOI & $\underline{\text { http://www.ncbi.nlm.nih.gov/pubmed/19319855 }}$ \\
\hline
\end{tabular}

This is a NIVEL certified Post Print, more info at http://www.nivel.eu

\title{
The role of companions in aiding older cancer patients to recall medical information
}

\author{
JESSE JANSEN ${ }^{1}$, JULIA C. M. VAN WEERT ${ }^{2}$, LEONIEK WIJNGAARDS-DE MEIJ ${ }^{3,4}$, SANDRA VAN \\ DULMEN $^{1}$, THEA J. HEEREN ${ }^{5}$ AND JOZIEN M. BENSING ${ }^{5}$ \\ ${ }^{1}$ NIVEL (Netherlands Institute for Health Services Research), Utrecht, The Netherlands \\ ${ }^{2}$ The Amsterdam School of Communications Research (ASCoR), University of Amsterdam, \\ Amsterdam, The Netherlands \\ ${ }^{3}$ Department of Psychology, Faculty of Social Sciences, Utrecht University, Utrecht, The \\ Netherlands \\ ${ }^{4}$ Department of Methodology and Statistics, Faculty of Social Sciences, Utrecht University, \\ Utrecht, The Netherlands \\ ${ }^{5}$ Symfora Group, Centers for Mental Health Care, Amersfoort, The Netherlands
}

\begin{abstract}
Objectives: This study investigates information recall in unaccompanied and accompanied older cancer patients and their companions.

Methods: One hundred cancer patients (aged X65 years) and 71 companions completed a recall questionnaire after a nursing consultation preceding chemotherapy treatment. Recall was checked against the actual communication in video-recordings of the consultations. Patients also completed measures of anxiety and memory-related beliefs.

Results: Findings revealed that recall in patient and companion couples together was higher than their separate recall scores (both proportional and absolute), indicating that they supplement each other. Proportionally, unaccompanied patients recalled almost as much as couples, whereas their absolute recall scores were lower. Younger age and higher education were associated with higher recall in both patients and companions. Patients' memory-related beliefs predicted the recall scores of their companions rather than their own recall score. When patients reported memory complaints, recall was lower in their companion. In contrast, when patients indicated that they did not understand all information, their companion recalled more.

Conclusions: These findings indicate that, although an interrelationship exists between recall in patients and their companions, accompanied patients are likely to benefit from the extra information that their companions remember.
\end{abstract}


Jansen, J., Weert, J.C.M. van, Wijngaards-de Meij, L., Dulmen, S. van, Heeren, T.J., Bensing, J.M. The role of companions in aiding older cancer patients to recall medical information.

Psycho-Oncology: 2010, 19(2), 170-179

\section{INTRODUCTION}

During health-care visits most older patients are accompanied by significant others such as a spouse or adult child [1-4]. Companions may facilitate, inhibit, or impede patient participation and autonomy [2,5-7]. In oncology, companions are more likely to be present at initial visits, immediately after cancer recurrence, and in the terminal phase of the disease rather than in a routine follow-up [8]. Apart from reduced patient participation [9], emotional support from doctors [10], and shared decision-making [9], the presence of companions has been found to increase patient understanding, involvement in the consultation and decisionmaking [2]. Others found no effects at all [3]. A study in a geriatric oncology setting showed that companions' roles include providing emotional support, transcribing information, assisting in decision-making, providing companionship, elaborating on patients' comments, advocating for the patient, interpreting information for the patient, and acting as a memory aid [11]. Similar roles have been reported by other studies $[1,12,13]$.

One reason older patients are accompanied to consultations is to help them understand and remember information provided by the health professional [1,2,11,12]. For older patients, bringing a companion to consultations is a potentially useful compensation tool for memory decline $[14,15]$. It is well established that as people age; they experience declining cognitive function [16-18] and more difficulty remembering medical information [19]. Of course, age does not exist in a vacuum. Factors such as gender, anxiety, level of education, and disease severity may interact with age to influence recall, or affect recall over and above the effect of age. Also, an interrelationship could exist between recall of information in patients and their companions. Recall scores of patients and their companions may be similar or dissimilar depending on for example the relationship between patient and companion (e.g. spouse or child). Beliefs people hold about their memory functioning can influence their memory performance $[20,21]$. When people have to remember information together, beliefs about their own cognitive abilities and beliefs of their partners' abilities influences whether they actively process information or (more or less) rely on their partner to remember information [22]. Recall of medical information is important for older patients because they should have sufficient comprehension to make informed choices, correctly follow treatment regimens, and recognize side effects that require medical attention. Also, lower recall has been identified as an important factor explaining nonadherence to treatment [23,24]. As the care of oncology patients is now primarily carried out at home, there is an increased reliance on caregivers [25], and some have even suggested that compliance with treatment is often more dependent upon caregivers than patients [26]. Altogether, this clearly suggests the importance of investigating information recall in both patients and their companions.

The purpose of this study is to: (1) examine the influence of companion presence on recall of information presented to older cancer patients by nurses in an educational session preceding chemotherapy treatment, (2) assess differences in (predictors of) recall between patients and companions, and (3) explore if patient and companion characteristics influence one another's recall.

\section{MATERIALS AND METHODS}

\section{Participants}

Consecutive new patients in 10 Dutch hospitals were recruited between February 2005 and July 2007. The Medical Ethical Committee of the University Medical Centre Utrecht, The Netherlands, granted permission for the study supplemented by local feasibility statements from all participating hospitals.

To be eligible for the study, patients had to meet the following inclusion criteria: (a) aged 65 years or older, (b) receiving chemotherapy for the first time or for the first time in 5 years, (c) not participating in a Phase III clinical trial, (d) sufficient command of the Dutch language, and (e) no cognitive impairment (indicated in the medical record). 
Jansen, J., Weert, J.C.M. van, Wijngaards-de Meij, L., Dulmen, S. van, Heeren, T.J., Bensing, J.M. The role of companions in aiding older cancer patients to recall medical information.

Psycho-Oncology: 2010, 19(2), 170-179

This study was part of a larger study investigating the effects of communication skills training. After pre-test, hospitals that participated in the study were randomized to receive communication training. As part of this training, nurses practised addressing the needs of patients as well as their companions. Because we think that this may influence the relation between accompaniment and recall of information, patients from the experimental hospitals at post-test were excluded (n525).

\section{Procedure}

Before the consultation, written informed consent to videotape the consultation was given by patients and nurses. Immediately after the consultation, patients completed a questionnaire, including background and disease characteristics, anxiety, recall, and memory-related beliefs. The companion identified as providing the greatest assistance in daily life was also asked to complete the recall questionnaire. A researcher was available to read the questions aloud, if necessary. If this was the case, patient and companion completed the recall questionnaire in separate rooms. Additional data were obtained on companions' age, gender, and level of education.

\section{Measurements}

\section{Recall of information}

Video observations: The videotapes were analysed using an observation checklist developed for this study, which is described extensively elsewhere [27]. An information item was defined as a segment of speech expressing a single idea concerning treatment and disease-related issues [28]. The categories in the checklist covered two main domains: (a) information about treatment and related issues (e.g. treatment details and cancer-specific information) and (b) recommendations on handling potential side effects (e.g. diet and hygiene). Additional elements discussed, but not included in the standard checklist, could be added to each category of the checklist, resulting in complete content analysis of the consultation (i.e. total amount of information discussed).

Recall Questionnaire: Recall was measured using a structured questionnaire, The 'Netherlands Patient Information Recall Questionnaire', which was developed in conjunction with the observation checklist [27]. Items recalled in response to eleven open-ended questions about treatment recommendations were compared with items mentioned by the nurse during the videotaped consultation. The number (absolute recall) and percentage (proportion recall) of facts recalled accurately were calculated in total and for each category separately.

Coding reliability: Two coders were trained. Discrepancies during training were resolved through discussion. The main coder observed all consultations. The other coded a random $20 \%$ of the main coder's consultations. Interrater reliability (mean Cohen's kappa) was 0.79 (range 0.05-1.0) for the content analysis of the videotapes and 0.96 (range 0.87-1.0) for coding responses to the recall questions [27].

Pooling recall data: If patients and their companions remember different types of information, they remember more as a couple than each of them independently. Recall in the patient and companion couple was pooled by summing the number of items they each recalled on each recall question [29]. For example if patient A recalled five items a-b-c-d-e and companion $B$ recalled five items a-b-c-f-g, pooled recall for the AB couple will be seven items a-b-c-d-e-f-g.

\section{Background and medical details}

Socio-demographic variables were assessed by a self-reporting questionnaire. Nurses or doctors provided medical details for each patient, including diagnosis and treatment goal (curative or palliative). 
Jansen, J., Weert, J.C.M. van, Wijngaards-de Meij, L., Dulmen, S. van, Heeren, T.J., Bensing, J.M. The role of companions in aiding older cancer patients to recall medical information.

Psycho-Oncology: 2010, 19(2), 170-179

\section{Anxiety}

Current levels of generalized anxiety were measured with the shortened version of the Dutch adaptation of the State-Trait Anxiety Inventory [30,31]. Respondents indicated their level of agreement (from 'not at all' to 'very much so' on a 4-point Likert scale) to each of the items, with raw scores summed to produce a total score (10-40). Cronbach's alpha for the scale was 0.87 .

\section{Memory-related beliefs}

Four questions were used to assess memory-related beliefs regarding the videotaped consultation using a 4-point Likert scale. Patients were asked to rate their level of attention during the consultation, their level of understanding of the information discussed, and their perceived likelihood of remembering the information. Because of the skewed distribution, scores on the attention question were dichotomized into 'high level of attention' (score 1) and 'not a high level of attention' (scores 2-4). Similarly, scores on the likelihood of remembering question were dichotomized into 'highly likely to remember' (score 1) and 'not highly likely to remember' (scores 2-4). For the level of understanding question, patients only used two of the four response options ('high level of understanding' and 'moderate level of understanding').

In addition, subjective memory complaints were assessed using the memory question of the Groningen Frailty Indicator (GFI) [32] ('do you have any complaints about your memory?’; 3-point Likert scale) and the European Organization for Research and Treatment of Cancer (EORTC) Quality of Life Questionnaire (QLQ-C30) (EORTC QLQ-C30) [33] ('in the last week, did you have difficulties remembering things?'; 4-point Likert scale). A dichotomous memory composite score was computed; 'no memory complaints' consisting of patients that indicated that they did not have any problems with their memory on both the GFI question and the EORTC question and 'memory complaints' consisting of the remaining patients.

\section{Statistical analysis}

To determine differences between participants and non-responders and patients with and without a companion, Chi-square tests and independent sample t-tests were used. Differences in recall between unaccompanied patients, accompanied patients, companions, and the pooled data were tested using independent and paired sample t-tests.

To assess the effect of companions and patients on one another's information recall, the Actor- Partner Interdependence Model (APIM) was used [34]. The APIM is appropriate when a dyad (i.e. patient-companion couple) is the unit of analysis and tests need to be performed both within and between dyads [35]. The heart of the APIM approach is to assess effects for both the actor and his or her partner. Use of the APIM allows one to assess not only whether an actor's own attributes predict his or her responses but also whether the attributes of the actor's partner predict the actor's responses while the impact of the actor's own attributes is controlled for [34]. In the current study, the actor effect estimates the effect that an actor's own score on the independent variable has on that person's outcome measure (e.g. either patient's age influencing his or her own recall or companion's age influencing his or her own recall). The partner effect estimates the effect that scores of the partner on the independent variable have on the actor's outcome (e.g. patient's age influencing companion's recall or companion's age influencing patient's recall). In the model, not only actor and partner effects of variables can be tested but several interactions involving actor and/or partner variables.

The APIM was tested, as recommended by Campbell and Kashy [36], within a multilevel regression analysis. A unique feature of multilevel analysis is that it works with a specific statistical model designed for nested data. In the current data there is a nested structure captured by a two-level hierarchy. The measurements of patients and companions (first level) are dependent and nested in a couple (second level). Couples are also nested with nurses (third level) and hospitals (fourth level) but since no variance in recall was found at 
Jansen, J., Weert, J.C.M. van, Wijngaards-de Meij, L., Dulmen, S. van, Heeren, T.J., Bensing, J.M. The role of companions in aiding older cancer patients to recall medical information.

Psycho-Oncology: 2010, 19(2), 170-179

these levels (i.e. Intraclass Correlation was 0.000 for both levels) we used a two-level model for the analysis. The following models were tested. Model 1 was a simple model with the variables individual (patient or companion) and relationship between patient and companion (spouse or adult child). In Model 2, the background characteristics (gender, age, and education) of the actor and the partner were introduced. To test whether there were different predictors of recall for patients and companions, interactions between individual (patient or companion) and the significant background characteristics were added. In Model 3, memoryrelated beliefs were introduced. Since no companion data was obtained for these variables, only the actor effect on the patient's outcome and the partner effect on the companion's outcome could be assessed. The final Model (Model 4) examined all the significant predictors of the previous models. To control for patient anxiety, treatment goal, consultation duration, and amount of information discussed, these variables were introduced to the final model, step by step. The analysis revealed a quadratic, rather than linear, relationship between percentage recall and the total amount of information presented. To account for this non-linearity, a second-order polynomial regressor (quadratic) was used for this variable [37]. To increase interpretability of the regression coefficients and because interaction terms were modelled, all continuous variables were centred [38] using the recommended approach for APIM. Analyses were performed with Statistical Package for the Social Sciences (SPSS) (version 16.0; SPSS Inc, Chicago, Ill) and MLwiN [39].

\section{RESULTS}

\section{Participants}

Figure 1 depicts a flowchart of the inclusion of patients in this study. A sample of 225 patients was recruited. Of these, 148 patients (66\%) gave informed consent to videotape the consultation, 77 patients refused to participate, 46 felt it was too much, 14 did not want to be videotaped, 5 felt too sick or too tired, and 12 refused for other reasons or without giving a reason. Participants and nonparticipants did not differ in gender or age. Twenty-five participants were excluded because they belonged to the experimental group in the post-test. One hundred and one of the resulting 123 patients (82\%) completed the recall questionnaire. One patient was later excluded because he or she was assisted in completing the questionnaire, leaving 100 patients. Patients with and without a recall questionnaire differed in gender (w2 (1)56.34, Po0.05), patients who completed the recall questionnaire were more likely to be male. There was no difference in age. Eighty-three of the patients who completed a recall questionnaire were accompanied to the consultation, 71 of these companions (86\%) filled out the recall questionnaire.

\section{[FIGURE 1]}

\section{Patient and companion characteristics}

Patient characteristics are shown in Table 1. Eighty-six percent of the patients were accompanied to the consultation, the majority (76\%) by one companion. There was a significant gender difference (w2 (1)54.67, Po0.05) and difference in living arrangements (w2(1)59.71, Po0.01) between patients with and without a companion. Unaccompanied patients were more often men, and more often lived alone. Consultations were longer when a companion was present (M557.37; SE51.41) than when patients were alone (M549.07; SE54.00, t(106)5_2.26, Po0.05) and nurses discussed more information in accompanied (M583.60; SE52.21) versus unaccompanied (M569.94; SE55.01, t(99)5_2.58, Po0.05) consultations. Finally, unaccompanied patients more often indicated that their level of attention during the consultation was high compared with accompanied patients (w2(1)53.88, Po0.05). No other significant differences were found.

Patients were most often accompanied by their spouses (66\%). For couples that completed 
Jansen, J., Weert, J.C.M. van, Wijngaards-de Meij, L., Dulmen, S. van, Heeren, T.J., Bensing, J.M. The role of companions in aiding older cancer patients to recall medical information. Psycho-Oncology: 2010, 19(2), 170-179

the recall questionnaire, differences between patient and companion were tested (not in table). Patients were significantly older compared with childcompanions and spousecompanions (patient M571.57; SE50.64 versus spouse, M568.38; SE51.14, t(81)52.55, Po0.05; patient M574.1; SE51.76 versus adult child M544.51; SE51.51, t(41)515.97, Po0.001). Furthermore, there was a significant gender difference between patients and companions if the companion was the patient's spouse (w2(1)534.10, Po0.001). As the majority of patients were men, spouse companions were more likely to be women. Also, companions who were an adult child of the patient were more highly educated than the patient (w2(2)513.55, Po0.01).

\section{[TABLE 1]}

\section{Recall}

Pooled recall

To explore if patients and companions supplemented each other in the type and amount of information they recalled, their recall data were pooled. As Table 2 presents, couples recalled significantly more information (proportional, M533.00; SE51.59; absolute, M511.35; SE50.66) than the individual patient (proportional, M520.09; SE51.19, t (70)5_12.33, Po0.001; absolute, M56.92; SE50.47, t(70)5_11.50, Po0.001) or companion (proportional, M523.32; SE51.50, t (70)5_10.87, Po0.001; absolute, M57.92; SE50.56, $t(70) 5 \_10.13$, Po0.001) on their own. Table 2 also depicts recall of the patients who came to the consultation alone. There was a trend showing that unaccompanied patients (M528.00; SE54.13) recalled proportionately more information than accompanied patients (M520.09; SE51.19, t(19)51.84, Po0.08), but absolute recall did not differ. More importantly, although patients and companions together remembered more than each of them separately, the proportion recalled by the couples (M533.00; SE51.59) did not significantly differ from the proportion recalled by the unaccompanied patients (M528.00; SE54.13, t(86)5_1.31, P40.05). However, when looking at the absolute recall scores, pooled recall was significantly higher (M511.35; SE50.66) than recall in the unaccompanied patients (M56.68; SE50.71, $\mathrm{t}(47) 5 \_4.84$, Po0.001).

\section{[TABLE 2]}

\section{Actor partner analyses}

A two-level model predicted recall significantly better than a one-level model (w2(1)510.87, Po0.001), warranting multilevel regression analysis. The Intraclass Correlation was 0.38 for the initial model indicating that there was a significant and fairly strong relationship between patient and companion recall.

Background characteristics (Models 1 and 2): The first model (see Table 3) shows that companions recalled more information than patients (B53.323, Po0.05) and adult child companions recalled more than spouse companions (B55.537, Po0.01). However, theses differences disappeared in successive models. After introducing background characteristics (age, gender, and education) of the actor and the partner, both age and education appeared to be significantly related to information recall in patients and companions (Model 2). Recall was lower when the person was older (B5_0.300, Po0.01), and when less educated (B57.225, Po0.01). To check whether effects differed for patients and companions, the interactions between the background variables and the variable individual (05patient, 15companion) were tested. These interactions were not significant, indicating that the effects of age and education were the same for patient and companion. Additionally, none of the background variables of the partner were significant.

Memory-related beliefs (Model 3): To look at the actor and partner effects of memoryrelated beliefs, these variables were introduced in Model 3. As companions did not complete 
Jansen, J., Weert, J.C.M. van, Wijngaards-de Meij, L., Dulmen, S. van, Heeren, T.J., Bensing, J.M. The role of companions in aiding older cancer patients to recall medical information.

Psycho-Oncology: 2010, 19(2), 170-179

these measures, only the actor effect on the patient's outcome and the partner effect on the companion's outcome could be assessed. Both patients' memory complaints and level of attention were negative predictors of companion recall. Companions whose partner (i.e. the patient) reported to have memory complaints recalled less information themselves (B5_6.884, Po0.01). Companions recalled less information if the patient indicated that their level of attention during the consultation was not high (B5_9.046, Po0.01). In contrast, if the patient indicated that they had a moderate (compared with high) level of understanding of the information presented, companions recalled more information (12.751, Po0.001). None of the actor effects were significant.

Final model (Model 4): In the final model, all variables that were significant in the previous models were introduced together. This model confirmed that recall was lower for older patients and companions (B5_0.317, Po0.01) and higher for patients and companions with a higher level of education (B56.846, Po0.01). Patients' memory complaints remained negatively and patients' subjective level of understanding positively associated with companion recall.

The introduction of possible confounding variables (patient anxiety, treatment goal, consultation duration, and amount of information discussed) did not result in significant changes, although it did reveal a negative effect of amount of information discussed (quadratic: B5_0.006, Po0.01). The more information nurses discussed, the less information patients and companions recalled with the significant negative quadratic component indicating that percentage recall deteriorates more rapidly when increasing amounts of information are discussed.

\section{[TABLE 3]}

\section{DISCUSSION}

The results of this study show that joint recall (both proportional and absolute) of couples was higher than patients' or companions' separate recall scores. Apparently, cancer patients and their companions supplement each other in the type of information they remember. Pooled absolute recall was also higher than absolute recall in unaccompanied patients, but no such effect was found for proportional recall. Echoing previous findings [10], when companions were present consultations were on average 8min longer and nurses discussed more information. This suggests that nurses are more selective in the information they give in unaccompanied visits, which may explain why unaccompanied patients recall almost an equal proportion of information on their own. It may also explain why there was a trend indicating that accompanied patients recalled proportionally less information than unaccompanied patients although there was no difference in absolute scores. A

Alternatively, accompanied patients may put less effort into remembering all the information presented because they assume their partner will recall it for them [15]. This explanation is supported by the fact that unaccompanied patients reported higher levels of attention during the consultation than accompanied patients. Previous studies have shown that one reason patients bring a companion is to help them remember information $[1,2,11,12]$. Perhaps patients who choose not to be accompanied do so partly because they expect not to need support in remembering information. To disentangle the effect of being accompanied versus the effect of patient characteristics associated with preference for being accompanied, a study design in which patients are randomly allocated to bring a companion or not is necessary [3]. A companion was present in $86 \%$ percent of the consultations in this study. The majority of patients (76\%) were accompanied by one companion, most often the spouse (66\%). Confirming earlier studies, accompanied patients were more often women [1]. The fact that in almost a quarter of the consultations two or more companions were present is worth mentioning, because the presence of more than one companion may make the consultation increasingly more complex. 
Jansen, J., Weert, J.C.M. van, Wijngaards-de Meij, L., Dulmen, S. van, Heeren, T.J., Bensing, J.M. The role of companions in aiding older cancer patients to recall medical information.

Psycho-Oncology: 2010, 19(2), 170-179

Patients who did not bring a companion were more likely to live alone than accompanied patients. Nevertheless, almost half of the unaccompanied patients (n58) did live with a partner or child(ren). Older patients seem to have established preferences for including or excluding significant others from medical consultations [3]. Present results suggest that, where recall is concerned, health professionals should accommodate these preferences rather than encouraging all patients to bring a companion. A cancer diagnosis is stressful for patients as well as their significant others and the presence of family and friends may provide emotional support [10, 11, 40]. A recent survey by Wolff and Roter [41] showed that accompanied patients were more satisfied with the communication and care provided by their physician than unaccompanied patients. In contrast, other authors reported that in some situations companions may negatively influence the encounter, especially if they strongly pursue their own agenda or interfere with the patient's communication [5, 9, 42]. The current study reveals that a more family-centred approach, attending to all persons present, may contribute to further understanding of accompanied encounters in oncology settings.

The APIM model was used to analyse the data, because this method allowed assessing the effect of patient and companion characteristics on their own recall scores, as well as the effect of their characteristics on their partner's recall scores. Our analysis showed that recall is lower for patients and companions with lower levels of education and for older patients and companions. Recall also decreased when increasing amounts of information were discussed. These findings are in line with previous studies [43]. Interestingly, we found that although patients' beliefs about their memory ability were not related to their own recall scores, they were related to recall in their companion. When patients reported memory complaints, companion recall was lower. This may indicate that companions of patients with memory complaints had memory complaints themselves. The majority of companions completing the recall questionnaire were the patients' spouses (66\%). While spouses were on average younger than the patient they accompanied, their average age was 68 years, making it not unlikely for companions to have memory complaints too. Analysis revealed that when patients indicated moderate rather than complete understanding of the information presented to them, their companions recalled more. This seems to be in apparent contrast with the previous finding. However, post-hoc analyses showed that although patients with memory complaints were as likely to be accompanied by a spouse as an adult child, there was a trend indicating that patients reporting a moderate level of understanding were more often accompanied by an adult child (w2(1)54.80, P50.057). The effect of companion recall on patient understanding may be explained by the child-companion's younger age and higher education. Perhaps these patients knew they would not understand all of the consultation, and asked their child to accompany them.

The current study has some limitations. Only a small number of patients in this study were unaccompanied (n517), the current results are tentative and should be replicated in a larger study with more statistical power. The memory-related beliefs questions were intended to tap into patients' beliefs about their ability to attend to, understand, and remember information discussed in the consultation. Recall was measured directly after consultations but patients completed most of the memory-related questions subsequent to the recall questionnaire. Therefore, these responses could have been a judgment of learning. It would be interesting to take the memory-related beliefs of the companion into account; unfortunately, the design of the larger study did not allow collecting these data for companions. The study is also limited in that it did not include objective measurements of patients' cognitive function. However, patients with non-age-related cognitive impairments (according to their medical record) were excluded, rendering it unlikely that patients with clear cognitive deficits such as dementia participated in this study. This was supported by measures of cognitive functioning in a subsample of 30 patients, using the Dutch version of the Telephone Interview for Cognitive Status [44], showing that none of them (except one patient who scored just one point below cut-off) fulfilled criteria for cognitive impairment. Since more than half of the patients reported memory complaints, it is very likely that patients and their companions may have 
Jansen, J., Weert, J.C.M. van, Wijngaards-de Meij, L., Dulmen, S. van, Heeren, T.J., Bensing, J.M. The role of companions in aiding older cancer patients to recall medical information.

Psycho-Oncology: 2010, 19(2), 170-179

had more subtle, age-related cognitive deficits. Finally, although this study showed beneficial effects of a companion's presence on recall as measured directly after the consultation, transfer of these effects to everyday functioning merits further study.

In summary, older cancer patients forget substantial amounts of the information presented in educational sessions about chemotherapy treatment but patients who bring a companion to the consultation are likely to benefit from the extra information that their companion will remember. Future studies should investigate the complex dynamics of the nurse-companionpatient interaction, with the ultimate aim of improving outcomes for older cancer patients and their families.

\section{ACKNOWLEDGEMENTS}

We thank the patients and nurses who participated in this study. Furthermore, we would like to thank Judith de Groot, Janneke Noordman, Jessika Ouwerkerk, and Marit Schotten for their help in data acquisition and Nienke van der Meulen and Frank Tol who participated in the coding of the videotaped encounters. We gratefully acknowledge the Dutch Cancer Society (grant number NIVEL 2003-2973) for funding this study.

\section{REFERENCES}

1. Glasser M, Prohaska T, Gravdal J. Elderly patients and their accompanying caregivers on medical visits. Res Aging 2001;23(3):326-348.

2. Clayman ML, Roter D, Wissow LS, Bandeen-Roche K. Autonomy-related behaviors of patient companions and their effect on decision-making activity in geriatric primary care visits. Social Sci Med 2005;60(7): 1583-1591.

3. Shields CG, Epstein RM, Fiscella $\mathrm{K}$ et al. Influence of accompanied encounters on patient-centeredness with older patients. J Am Board Fam Pract 2005;18(5): 344-354.

4. Eggly S, Penner LA, Greene M, Harper FW, Ruckdeschel JC, Albrecht TL. Information seeking during 'bad news' oncology interactions: question asking by patients and their companions. Soc Sci Med 2006; 63(11):2974-2985.

5 . Beisecker $A E$. The influence of a companion on the doctor-elderly patient interaction. Health Commun 1989;1(1):55-70.

6. Hasselkus BR. Physician and family caregiver in the medical setting —negotiation of care. J Aging Stud 1992;6(1):67-80.

7. Adelman RD, Greene MG, Charon R. The physician- elderly patient-companion triad in the medical encounter: the development of a conceptual framework and research agenda. Gerontologist 1987;27(6):729-734.

8. Merckaert I, Libert Y, Delvaux N, Razavi D. Breast cancer: communication with a breast cancer patient and a relative. Ann Oncol 2005;16:209-212.

9. Greene MG, Majerovitz SD, Adelman RD, Rizzo C. The effects of the presence of a third person on the physician-older patient medical interview. J Amer Geriatr Soc 1994;42(4):413-419.

10. Labrecque MS, Blanchard CG, Ruckdeschel JC, Blanchard EB. The impact of family presence on the physician-cancer patient interaction. Soc Sci Med 1991;33(11):12531261.

11. Ellingson LL. The roles of companions in geriatric patient-interdisciplinary oncology team interactions. J Aging Stud 2002;16(4):361-382.

12. Schilling LM, Scatena L, Steiner JF, Albertson GA, Lin CT, Cyran L, Ware L, Anderson $\mathrm{RJ}$. The third person in the room: frequency, role, and influence of companions during primary care medical encounters. J Fam Pract 2002;51(8):685-690.

13. Beisecker AE, Moore WP. Oncologists' perceptions of the effects of cancer patients' companions on physicianpatient interactions. J Psychosoc Oncol 1994; 12(1/2):23-39.

14. Gould ON, Osborn C, Krein H, Mortenson M. Collaborative recall in married and unacquainted dyads. Int J Behav Dev 2002;26(1):36-44.

15. Johansson NO, Andersson J, Ronnberg J. Compensating strategies in collaborative remembering in very old couples. Scand J Psychol 2005;46(4):349-359. 
Jansen, J., Weert, J.C.M. van, Wijngaards-de Meij, L., Dulmen, S. van, Heeren, T.J., Bensing, J.M. The role of companions in aiding older cancer patients to recall medical information.

Psycho-Oncology: 2010, 19(2), 170-179

16. Bopp KL, Verhaeghen P. Aging and verbal memory span: a meta-analysis. J Gerontol Ser B-Psychol Sci Soc Sci 2005;60(5):223-233.

17. Salthouse TA. The processing-speed theory of adult age differences in cognition.

Psychol Rev 1996;103(3): 403-428.

18. Grady CL, Craik FI. Changes in memory processing with age. Curr Opin Neurobiol 2000;10(2):224-231.

19. Brown SC, Park DC. Theoretical models of cognitive aging and implications for translational research in medicine. Gerontologist 2003;43(1):57-67.

20. Neupert SD, McDonald-Miszczak L. Younger and older adults' delayed recall of medication instructions: the role of cognitive and metacognitive predictors. Aging Neuropsychol Cogn 2004;11(4):428-442.

21. Hess TM. Memory and aging in context. Psychol Bull 2005;131(3):383-406. 22. Berg CA, Smith TW, Ko KJ, Henry NJM, Florsheim P, Pearce G, Uchino BN, Skinner MA, Beveridge RA, Story N, Glazer K. Task control and cognitive abilities of self and spouse in collaboration in middle-aged and older couples. Psychol Aging 2007;22(3):420-427. 23. Ley P. Satisfaction, compliance and communication. Br J Clin Psychol 1982;21(4):241254.

24. Kessels RPC. Patients' memory for medical information. J Roy Soc Med 2003;96(5):219-222.

25. Haley WE. The costs of family caregiving: implications for geriatric oncology. Crit Rev Oncol/Hematol 2003;48(2):151-158.

26. Beisecker AE, Brecheisen MA, Ashworth J, Hayes J. Perceptions of the role of cancer patients' companions during medical appointments. J Psychosoc Oncol 1996;14(4):29-45.

27. Jansen J, van Weert J, van der Meulen N, van Dulmen S, Heeren T, Bensing J. Recall in older cancer patients: measuring memory for medical information. Gerontologist 2008;48(2):149-157.

28. Dunn SM, Butow PN, Tattersall MHN, Jones QJ, Sheldon JS, Taylor JJ, Sumich MD. General information tapes inhibit recall of the cancer consultation. J Clin Oncol 1993;11(11):2279-2285.

29. Meudell PR, Hitch GJ, Kirby P. Are 2 heads better than one-experimental investigations of the social facilitation of memory. Appl Cogn Psychol 1992;6(6):525-543.

30. van der Ploeg HM, Defares PB, Spielberger CD. Handleiding bij de Zelfbeoordelings Vragenlijst (ZBV) [Manual of the Dutch version of the State Trait Anxiety Inventory]. Swets and Zeitlinger: Lisse, 1980.

31. Spielberger CD. State-Trait Anxiety Inventory (Selfevaluation Questionnaire). Consulting Psychologists Press: Palo Alto University, CA, 1983.

32. Schuurmans H, Steverink N, Lindenberg S, Frieswijk N, Slaets JP. Old or frail: what tells us more? J Gerontol Ser A-Biol Sci Med Sci 2004;59(9):M962-M965.

33. Aaronson NK, Ahmedzai S, Bergman B, Bullinger M, Cull A, Duez NJ, Filiberti A, Flechtner H, Fleishman SB, de Haes JC. The European Organization for research and treatment of cancer QLQ-C30: a qualityof- life instrument for use in international clinical trials in oncology. J Nat Cancer Inst 1993;85(5):365-376.

34. Kenny DA, Mannetti L, Pierro A, Livi S, Kashy DA. The statistical analysis of data from small groups. J Pers Soc Psychol 2002;83(1):126-137.

35. Kenny DA. Models of non-independence in dyadic research. J Soc Pers Relationships 1996;13(2):279-294.

36. Campbell L, Kashy DA. Estimating actor, partner, and interaction effects for dyadic data using PROC MIXED and HLM: A user-friendly guide. Pers Relationships 2002;9(3):327342.

37. Fox J. Applied Regression Analysis, Linear Models, and Related Methods. Sage: London, 1997.

38. Hox J. Multilevel Analysis: Techniques and Applications. Erlbaum: Mahwah, NJ, 2002.

39. Rasbash J, Browne W, Goldstein H, Yang M, Plewis I, Healy M. A User's Guide to MlwiN, University of London, Multilevel Models Project, 2000.

40. Street RL, Gordon HS. Companion participation in cancer consultations. PsychoOncology 2008;17(3): 244-251.

41. Wolff JL, Roter DL. Hidden in plain sight-medical visit companions as a resource for vulnerable older adults. Arch Int Med 2008;168(13):1409-1415. 
Jansen, J., Weert, J.C.M. van, Wijngaards-de Meij, L., Dulmen, S. van, Heeren, T.J., Bensing, J.M. The role of companions in aiding older cancer patients to recall medical information.

Psycho-Oncology: 2010, 19(2), 170-179

42. Ishikawa H, Hashimoto H, Roter DL, Yamazaki Y, Takayama T, Yano E. Patient contribution to the medical dialogue and perceived patient-centeredness - an observational study in Japanese geriatric consultations. J General Int Med 2005;20(10): 906-910.

43. Jansen J, Butow PN, van Weert JC et al. Does age really matter? Recall of information presented to newly referred patients with cancer. J Clin Oncol 2008;26(33): 5450-5457. 44. Kempen GI, Meier AJ, Bouwens SF, van Deursen J, Verhey FR. [The psychometric properties of the Dutch version of the Telephone Interview Cognitive Status (TICS)]. Tijdschrift voor Gerontologie en Geriatrie 2007; 38(1):38-45.

\section{FIGURES AND TABLES}

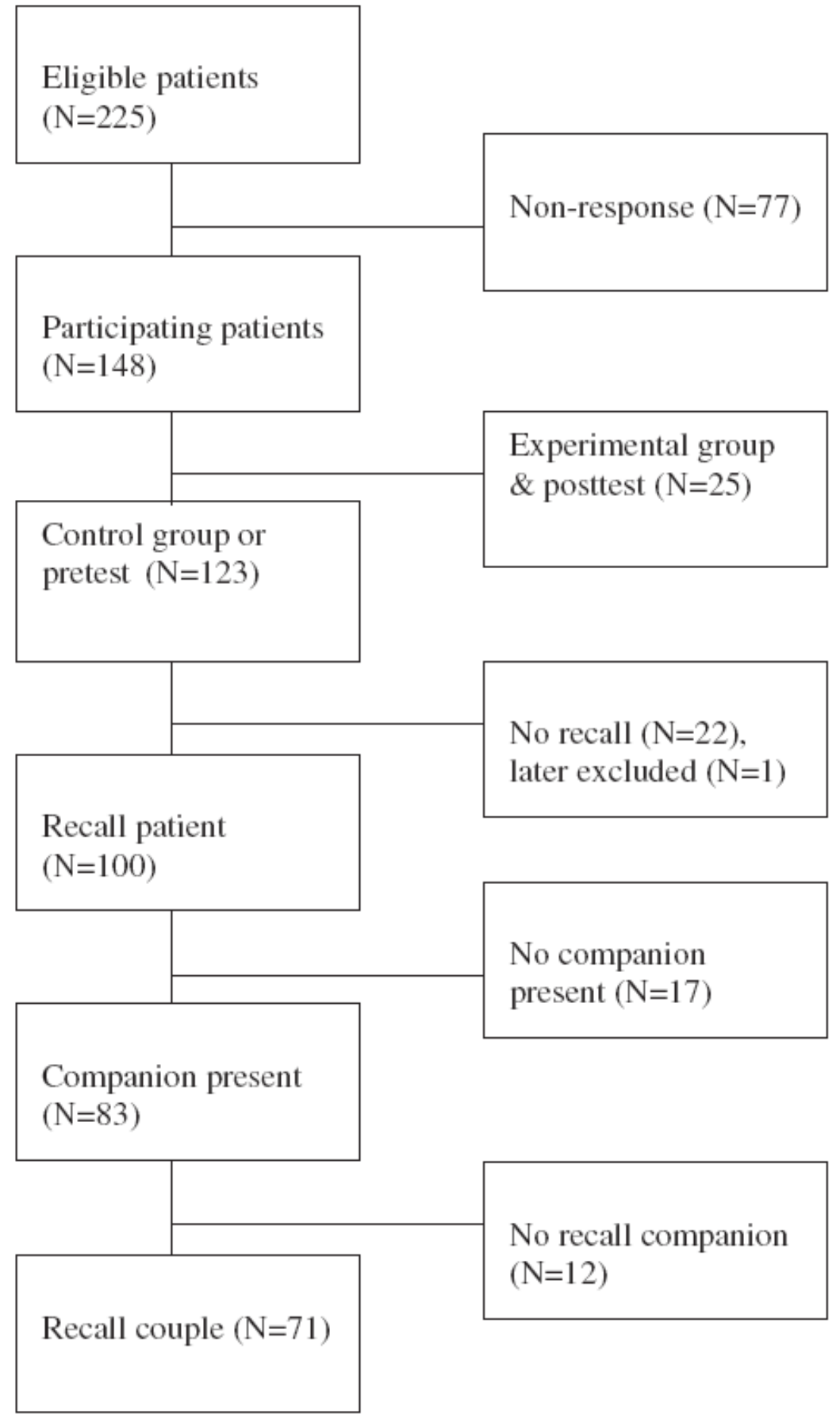

Figure I. Flowchart of participants 
Jansen, J., Weert, J.C.M. van, Wijngaards-de Meij, L., Dulmen, S. van, Heeren, T.J., Bensing, J.M. The role of companions in aiding older cancer patients to recall medical information.

Psycho-Oncology: 2010, 19(2), 170-179

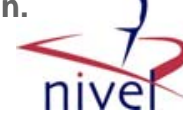

Table I. Characteristics of patients with and without companion ${ }^{\mathrm{ab}}$

\begin{tabular}{|c|c|c|c|c|}
\hline & \multicolumn{2}{|c|}{ With companion } & \multicolumn{2}{|c|}{ Without companion } \\
\hline & $N$ & $\%$ & $N$ & $\%$ \\
\hline Number of patients & 106 & 86.2 & 17 & 13.8 \\
\hline \multicolumn{5}{|l|}{ Gender* } \\
\hline Female & 41 & 38.7 & 2 & 11.8 \\
\hline Male & 65 & 61.3 & 15 & 88.2 \\
\hline \multicolumn{5}{|l|}{ Age } \\
\hline Mean (range) & \multicolumn{2}{|c|}{$72.1(65.0-85.7)$} & \multicolumn{2}{|c|}{$72.8(65.5-81.9)$} \\
\hline SD & \multicolumn{2}{|c|}{4.6} & \multicolumn{2}{|c|}{4.7} \\
\hline $\mathrm{N}$ & \multicolumn{2}{|c|}{106} & \multicolumn{2}{|c|}{17} \\
\hline \multicolumn{5}{|l|}{ Educational level } \\
\hline Low & 54 & 52.4 & 7 & 41.2 \\
\hline Middle & 22 & 21.4 & 2 & 11.8 \\
\hline High & 27 & 26.2 & 8 & 47.1 \\
\hline \multicolumn{5}{|l|}{ Living arrangements ${ }^{* *}$} \\
\hline With spouse/children & 84 & 81.6 & 8 & 47.1 \\
\hline Alone & 19 & 18.4 & 9 & 52.9 \\
\hline \multicolumn{5}{|l|}{ Children } \\
\hline Yes & 91 & 89.2 & 12 & 70.6 \\
\hline No & 11 & 10.8 & 5 & 29.4 \\
\hline \multicolumn{5}{|l|}{ Diagnosis } \\
\hline Digestive/gastrointestinal & 47 & 44.3 & 4 & 23.5 \\
\hline Lung & 25 & 23.6 & 5 & 29.4 \\
\hline Genitourinary & 11 & 10.4 & 2 & 11.8 \\
\hline Breast & 9 & 8.5 & 1 & 5.9 \\
\hline Haematologic & 9 & 8.5 & 3 & 17.6 \\
\hline Gynaecologic & 4 & 3.8 & 2 & 11.8 \\
\hline Other & 1 & 0.9 & 0 & 0.0 \\
\hline \multicolumn{5}{|l|}{ Treatment goal } \\
\hline Curative & 24 & 29.6 & 3 & 20.0 \\
\hline Palliative & 57 & 70.4 & 12 & 80.0 \\
\hline \multicolumn{5}{|l|}{ Time since diagnosis (months) } \\
\hline Mean (range) & & & & \\
\hline SD & & & & \\
\hline N & & & & \\
\hline State anxiety ${ }^{y}$ & & & & \\
\hline Mean (range) & & & & \\
\hline SD & & & & \\
\hline$N$ & & & & \\
\hline Memory-related beliefs & & & & \\
\hline Subjective memory complair & & & & \\
\hline No & 59 & 55.7 & 10 & 58.8 \\
\hline Not no & 47 & 44.3 & 7 & 41.2 \\
\hline Perceived level of attention & & & & \\
\hline High & 59 & 70.2 & 15 & 93.8 \\
\hline Not high & 25 & 29.8 & 1 & 6.2 \\
\hline Likelihood of remembering & & & & \\
\hline High & 33 & 39.8 & 10 & 62.5 \\
\hline Not High & 50 & 60.2 & 6 & 37.5 \\
\hline Perceived level of understan & & & & \\
\hline High & 66 & 78.6 & 15 & 93.8 \\
\hline Moderate & 18 & 21.4 & 1 & 6.2 \\
\hline Consultation characteristics & & & & \\
\hline Consultation duration (min) & & & & \\
\hline Mean (range) & & & & \\
\hline SD & & & & \\
\hline N & & & & \\
\hline Amount of information tota & & & & \\
\hline Mean (range) & & & & \\
\hline SD & & & & \\
\hline N & & & & \\
\hline
\end{tabular}

aNumbers do not always add up to 123 due to missing values.

'Tested for differences between patients with and without a companion.

'Normal range: 10-40, higher scores indicate greater anxiety.

${ }^{*} P<0.05,{ }^{* *} P<0.01$ 
Jansen, J., Weert, J.C.M. van, Wijngaards-de Meij, L., Dulmen, S. van, Heeren, T.J., Bensing, J.M. The role of companions in aiding older cancer patients to recall medical information.

Psycho-Oncology: 2010, 19(2), 170-179

Table 2. Recall of recommendations: patients, companions and pooled data

\begin{tabular}{|c|c|c|c|c|c|c|}
\hline Category $^{\mathrm{a}}$ & $\begin{array}{c}\text { No. of patients } \\
\text { (without } \\
\text { companion) }^{\mathrm{b}}\end{array}$ & $\begin{array}{c}\text { Patient without } \\
\text { companion recall } \\
(\%,(S D))\end{array}$ & $\begin{array}{c}\text { No. of } \\
\text { patients/ } \\
\text { companions }^{\mathrm{b}}\end{array}$ & $\begin{array}{c}\text { Patient recall } \\
(\%,(\text { SD }))\end{array}$ & $\begin{array}{c}\text { Companion } \\
\text { recall (\%, (SD)) }\end{array}$ & $\begin{array}{c}\text { Pooled } \\
\text { recall }(\%,(S D))\end{array}$ \\
\hline Total recall (absolute) ${ }^{c 3, d 3, f 3}$ & 17 & $6.7(2.3)$ & 71 & $6.9(4.0)$ & $7.9(4.7)$ & | I.4 (5.5) \\
\hline Total recall $(\%)^{c 3, d 3, \text { el }}$ & 17 & $28.0(17.0)$ & 71 & $20.1(10.0)$ & $23.3(12.7)$ & $33.0(13.4)$ \\
\hline \multicolumn{7}{|l|}{ Side effects } \\
\hline Skin and hair ${ }^{\mathrm{c3}, \mathrm{d} 3}$ & 15 & $44.1(32.4)$ & 67 & $32.5(30.1)$ & $33.6(30.1)$ & $43.2(30.6)$ \\
\hline Mouth $^{\mathrm{c}, \mathrm{d}} \mathrm{d} 3$ & 15 & $30.4(31.2)$ & 68 & $25.4(23.1)$ & $27.1(26.5)$ & $40.4(25.7)$ \\
\hline Digestive system ${ }^{c 3}$, d3, el & 16 & $27.8(23.7)$ & 69 & $19.3(14.6)$ & $24.4(19.6)$ & $31.7(20.0)$ \\
\hline Stools ${ }^{\mathrm{cl}, \mathrm{d} 2 \text { el }}$ & 10 & $30.0(42.2)$ & 50 & $29.9(39.7)$ & $19.7(33.3)$ & $35.6(4 \mid .1)$ \\
\hline Eating and drinking $\mathrm{g}^{\mathrm{c}, \mathrm{d} 3, \mathrm{e} 2}$ & 15 & $29.0(30.8)$ & 65 & $19.1(16.2)$ & $26.7(22.4)$ & $33.5(23.1)$ \\
\hline Hygiene $^{c 3, d 3}$ & 13 & $42.4(29.5)$ & 66 & $23.1(21.0)$ & $27.1(21.1)$ & $38.9(22.1)$ \\
\hline General well-being and fatigue ${ }^{c 3, d 3}$ & 12 & $34.7(37.2)$ & 61 & $24.3(28.9)$ & $24.6(26.1)$ & $36.3(31.0)$ \\
\hline \multicolumn{7}{|l|}{ Miscellaneous } \\
\hline Psychosocial issues ${ }^{\mathrm{cl}, \mathrm{d} 2}$ & 8 & $12.5(35.4)$ & 35 & $24.1(36.1)$ & $13.3(28.3)$ & $32.4(38.3)$ \\
\hline Daily life $\mathrm{el}^{\mathrm{cl}}$ & 5 & $50.0(50.0)$ & 26 & $11.5(29.4)$ & $26.9(49.5)$ & $32.7(52.8)$ \\
\hline Side effects to report ${ }^{c 3, d 3}$ & 17 & $24.1(31.5)$ & 71 & $16.9(15.1)$ & $20.1(15.6)$ & $29.6(18.7)$ \\
\hline
\end{tabular}

${ }^{2}$ Recall for the different categories was calculated over all consultations in which at least one item from the category was discussed; differences between companion and pooled recall were only tested for total recall (\% and absolute).

${ }^{b}$ Refers to the number of consultations in which at least one item from the category was discussed.

${ }^{c}$ Refers to differences in recall between patient and pooled data, ${ }^{d}$ refers to differences in recall between companion and pooled data, ${ }^{\mathrm{e}}$ refers to differences in recall between patient and companion, and 'refers to difference in recall between unaccompanied patient and pooled recall. ${ }^{1} P<0.05 ;{ }^{2} p<0.01 ;{ }^{3} P<0.001$.

Table 3. Summary of the actor-partner interdependence model analysis for patient and companion recall

\begin{tabular}{|c|c|c|c|c|c|c|c|c|}
\hline & \multicolumn{2}{|c|}{ Model I } & \multicolumn{2}{|c|}{ Model 2} & \multicolumn{2}{|c|}{ Model 3} & \multicolumn{2}{|c|}{ Model 4} \\
\hline & B & (SE) & B & (SE) & B & (SE) & B & (SE) \\
\hline Individual $(0=$ patient $\mathrm{I}=$ companion $)$ & $3.323^{*}$ & $(1.530)$ & -3.217 & $(2.409)$ & 1.071 & $(2.810)$ & 1.264 & $(2.255)$ \\
\hline Relationship $(0=$ spouse $1=$ adult child $)$ & $5.537^{* *}$ & $(2.305)$ & & & & & & \\
\hline Actor age & & & $-0.300^{* *}$ & $(0.100)$ & & & $-0.317^{* *}$ & $(0.104)$ \\
\hline Actor gender $(0=$ male, $I=$ female $)$ & & & 1.235 & (2.844) & & & & \\
\hline \multicolumn{9}{|l|}{ Actor education $(0=\text { low })^{b}$} \\
\hline Middle & & & 3.571 & $(2.501)$ & & & 2.728 & $(2.231)$ \\
\hline High & & & $7.225^{* *}$ & $(2.533)$ & & & $6.846^{* *}$ & $(2.267)$ \\
\hline \multicolumn{9}{|c|}{ Effects of patient's memory related beliefs on companion recall (partner) } \\
\hline Memory complaints $(0=$ no $\mid=$ not no $)$ & & & & & $-6.884^{* *}$ & $(2.869)$ & $-6.642^{* *}$ & $(2.815)$ \\
\hline Perceived level of attention ( $0=$ high $\mathrm{I}=$ not high $)$ & & & & & $-9.046^{* *}$ & (3.426) & $-2.14 \mid$ & $(3.074)$ \\
\hline Perceived level of understanding ( $0=$ high $I=$ moderate $)$ & & & & & $|2.75|^{* * *}$ & $(4.105)$ & $7.603^{*}$ & (3.634) \\
\hline Likelihood of remembering $(0=$ high $1=$ not high $)$ & & & & & 5.766 & (3.036) & & \\
\hline
\end{tabular}

anteractions between individual and background characteristics were not significant and are therefore not shown in this table.

bEffect tested using Chi-square $\left(\chi^{2}\right)$ test statistic.

${ }^{*} P<0.05,{ }^{* *} p<0.01,{ }^{* * *} p<0.001$. 